\title{
Adherence to recommendations for early repeat cervical smear tests
}

\author{
Heather Mitchell, Gabriele Medley
}

\begin{abstract}
Objective-To assess adherence to recommendations for an early repeat cervical smear test in women with reports of cytological abnormalities, and to evaluate the impact of reminder letters to medical practitioners when such smear tests are overdue.
\end{abstract}

Design-Observational study.

Setting-Cytology (gynaecological) service for Victoria, Australia.

Subjects - Two groups of women who had abnormal cervical smears during 1985 . Women in group A had some evidence of an important dysplasia and were advised to have a repeat smear in three months' time whereas women in group B had a less serious abnormality and were advised to have a repeat smear test in six months' time. In all, 971 of the 1036 women in group $A$ and 1401 of the 1464 women in group B were eligible to have a repeat smear analysed by the service.

Intervention-If a repeat smear had not been received within three months of the recommended date a reminder letter generated by the service's computer was sent to the medical practitioner who had taken the smear.

End point-Thirty six months after the report on the abnormal smear was issued.

Measurements and main results -In all, $870(90 \%)$ of the women in group $A$ and $1154(82 \%)$ of the women in group B had a repeat smear test. The mean time to a repeat test was 3.0 months $(95 \%$ confidence interval 0.5 to 16.4 ) in group $A$ and 6.0 months $(1 \cdot 2$ to 30.3$)$ in group $B$. The reminder letter to the practitioner potentially increased the rate of return for a repeat smear test by $18 \%$ in group $A$ and $24 \%$ in group $B$. Adherence to the recommendation for a repeat test increased with increasing age.

Conclusions-Achieving high rates of follow up smear tests and appropriate management in women with cytological abnormalities is critical to the impact of a screening programme for cervical cancer. The reminder system used in this study was not labour intensive or expensive and provided a fail safe mechanism for ensuring that reports of abnormal smears were not overlooked.

Victorian Cytology (Gynaecological) Service, PO Box 253B, Melbourne, Victoria 3001, Australia Heather Mitchell, FRACP, epidemiologist Gabriele Medley, FRCPA, director

Correspondence to: $\mathrm{Dr}$ Mitchell.

\section{Introduction}

In itself a cervical smear test does nothing to alter a woman's risk of cervical cancer; the risk is reduced by appropriate management of precursor lesions that are detected on cervical screening. Women's acceptance of such management is therefore critical to the impact of a screening programme on the incidence of and mortality from cervical cancer. Few Australian women seem to decline management of abnormalities of the severity of carcinoma in situ or worse. ${ }^{12}$ There is, however, concern about an apparently high rate of default among women with less severe abnormalities, and recently this has been proposed as a reason for advocating treatment for all such lesions, even before their potential to progress to cervical neoplasia may be apparent. ${ }^{3+}$

We studied the adherence to recommendations for early repeat cervical smear tests among two groups of women in whom abnormalities had been reported by our service.

\section{Subjects and methods}

We attach routinely to all reports on cervical cytology issued by our service a recommendation either for the timing of the next cervical smear test or for further investigations if the results of cytological examination suggest important or persistent abnormalities. The service is the main laboratory for reporting results of cervical smear tests in Victoria and receives about 250000 specimens a year-about $75 \%$ of all cervical smears taken in Victoria. Women are not charged for the analysis of the smears. The laboratory's records are stored on a computer, and record linkage is routine.

Two groups of women who had cytological abnormalities reported during 1985 were selected for study. One group (group A) comprised women whose cervical smear was reported as follows.

\section{Inconclusive: cells of uncertain importance}

There are abnormal epithelial cells that have some features of human papillomavirus ("wart virus") infection. However, other features are more suggestive of a significant dysplasia (cervical intraepithelial neoplasia). Please repeat smear in 3 months.

The second group (group B) comprised women with a less serious degree of cytological abnormality. A dif$x$-ferent heading was used for the report, the wording of the report was less worrying, and a longer time interval was recommended until a repeat test. The report was as follows.

\section{Benign abnormalities present}

There are abnormal epithelial cells present which have features suggestive of human papillomavirus ("wart virus") infection. However, some of the changes are such that mild dysplasia (cervical intraepithelial neoplasia grade I) cannot be excluded. Please repeat smear in 6 months.

For both groups, if a repeat smear had not been received within three months of the recommended date the medical practitioner who took the abnormal smear was sent a reminder letter generated by the computer. The records were searched for the proportion of women in the two groups who adhered to the recommendations. Data were censored with respect to compliance 36 months after the report on the abnormal smear was issued.

Variation in compliance with these recommendations was sought according to the age of the woman, type of practitioner who had taken the abnormal 
smear, social class of the woman, and area of residence (metropolitan area of Melbourne or rural Victoria). Local government areas were assigned a social class according to a scale with five groups developed by principal component analysis of census information. ${ }^{5}$

\section{Results}

There were 1036 women in group A and 1464 women in group B. We were notified of 65 women from group A and 63 from group B whose repeat cervical smears were sent to other laboratories or whose follow up of the abnormal smear entailed a cervical biopsy or diathermy, or both. Thus 971 women from group A and 1401 women from group B were eligible to have further cervical smears analysed by the service.

We received further cervical smears within 36 months of the abnormal report being issued from 870 (90\%) women in group A and $1154(82 \%)$ in group B. Among the 348 women from whom no further smears were received were 60 whose medical practitioner notified us that he or she had not been successful in either contacting the woman or convincing the woman that a further test was desirable. For the remaining 288 women there was no response from the medical practitioner to the reminder letter for repeat smears.

Table I shows the range of times to a repeat smear test for the women in both groups. The median time was 3.0 months for the women in group A and 6.5 months for the women in group B. After logarithmic transformations the mean time to a repeat smear test was determined as 3.0 months for group A $(95 \%$ confidence interval 0.5 to 16.4 months) and 6.0 months for group B (1.2 to 30.3 months). These mean times were significantly different $(t=-38 \cdot 07, \mathrm{df}=2022$, $\mathrm{p}<0.0001$ ).

By the time the reminder letters were due to be posted $703(72 \%)$ of the 971 women in group A had been rescreened $(81 \%$ of the women who were eventually rescreened within the service). In group B 807 $(58 \%)$ of the 1401 women had been rescreened $(70 \%$ of the women who were eventually rescreened within the service). The reminder letter potentially increased the rate of repeat smear tests by $18 \%$ (from $72 \%$ to $90 \%$ ) for women in group A and by $24 \%$ (from $58 \%$ to $82 \%$ ) for women in group $\mathbf{B}$.

In both groups there was closer adherence to the

TABLE II - Percentages (proportions) of women with abnormal smears who had repeat cervical smear tests and of those who had repeat tests within recommended time according to age

\begin{tabular}{|c|c|c|c|c|}
\hline \multirow[b]{2}{*}{ Age } & \multicolumn{2}{|c|}{ Women who had repeat test } & \multicolumn{2}{|c|}{$\begin{array}{l}\text { Women who had repeat test } \\
\text { within recommended time }\end{array}$} \\
\hline & $\begin{array}{l}\text { Group } A^{\star} \\
(n=971)\end{array}$ & 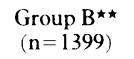 & $\underset{(n=971)}{\text { Group } A^{\star \star}}$ & $\begin{array}{l}\text { Group B } \\
(\mathbf{n}=1399)\end{array}$ \\
\hline$<20$ & $80(109 / 136)$ & $74(147 / 198)$ & $31 \quad(42 / 136)$ & $33(66 / 198)$ \\
\hline $20-29$ & $91(541 / 597)$ & $83(670 / 812)$ & $46(275 / 597)$ & $36(291 / 812)$ \\
\hline $30-39$ & $92(169 / 183)$ & $85(224 / 263)$ & $47(86 / 183)$ & $38(101 / 263)$ \\
\hline$>39$ & $93(51 / 55)$ & $90(113 / 126)$ & $71(39 / 55)$ & $40(51 / 126)$ \\
\hline
\end{tabular}

$\gamma_{\text {. Test for linear trend: }{ }^{\star} \mathrm{p}<0.01,{ }^{\star \star} \mathrm{p}<0.001}$

TABLE III - Percentages (proportions) of women with abnormal smears who had repeat cervical smear tests and who had repeat tests within recommended time according to type of practitioner who took abnormal smear or type of clinic where it was taken

\begin{tabular}{|c|c|c|c|c|}
\hline & \multicolumn{2}{|c|}{ Women who had repeat test } & \multicolumn{2}{|c|}{$\begin{array}{l}\text { Women who had repeat test within } \\
\text { recommended time }\end{array}$} \\
\hline & $\begin{array}{l}\text { Group A } \\
(\mathrm{n}=971)\end{array}$ & $\begin{array}{l}\text { Group B } \\
(n=1401)\end{array}$ & $\begin{array}{l}\text { Group A } \\
(\mathbf{n}=971)\end{array}$ & $\begin{array}{l}\text { Group B } \\
(n=1401)\end{array}$ \\
\hline Community health centre & $95(20 / 21)$ & $86(32 / 37)$ & $52(11 / 21)$ & $38(14 / 37)$ \\
\hline Family planning clinic & $93(74 / 80)$ & $82(96 / 117)$ & $51(41 / 80)$ & $49(57 / 117)$ \\
\hline General practitioner & $92(603 / 659)$ & $84(712 / 844)$ & $45(298 / 659)$ & $34(283 / 844)$ \\
\hline Gynaecologist & $84(98 / 116)$ & $82(201 / 245)$ & $39(45 / 116)$ & $35(85 / 245)$ \\
\hline Hospital & $82(27 / 33)$ & $61(38 / 62)$ & $55(18 / 33)$ & $29(18 / 62)$ \\
\hline Pregnancy termination centre & $80(16 / 20)$ & $50 \quad(9 / 18)$ & $40 \quad(8 / 20)$ & $11(2 / 18)$ \\
\hline Sexually transmitted diseases clinic & $76(32 / 42)$ & $85(66 / 78)$ & $50(21 / 42)$ & $64(50 / 78)$ \\
\hline
\end{tabular}

TABLE IV - Percentages (proportions) of women with abnormal smears who did not have a repeat cervical smear test according to social class'

\begin{tabular}{lcc}
\hline $\begin{array}{l}\text { Fifths of } \\
\text { social class }\end{array}$ & $\begin{array}{l}\text { Group A } \\
(\mathbf{n}=916)\end{array}$ & $\begin{array}{c}\text { Group B } \\
(\mathbf{n}=1332)\end{array}$ \\
\hline 1 (Highest) & $8(30 / 376)$ & $14(85 / 599)$ \\
2 & $7(8 / 108)$ & $18(30 / 168)$ \\
3 & $8(14 / 166)$ & $19(41 / 214)$ \\
4 & $8(8 / 98)$ & $18(24 / 132)$ \\
5 (Lowest) & $17(28 / 168)$ & $17(37 / 219)$ \\
\hline
\end{tabular}

recommendation for repeat smear tests with increasing age. This trend was apparent both in the proportion of women who had a repeat smear test and in the proportion who had a repeat test within the recommended time (table II). Two women in group B did not have their age stated on the original request form; neither had further tests within the service, and both are excluded from table II. $\chi^{2}$ Tests for linear trend with age were significant for three of the four sets of data in table II.

Table III shows the proportions of women who had repeat cervical smear tests and who had repeat tests within the recommended time according to the type of practitioner who took the abnormal smear or the type of clinic where it was taken. For both groups hospitals and the pregnancy termination centre had lower than average proportions of women having repeat smear tests. Community health centres had the highest proportions of women who had further tests. General practitioners, the pregnancy termination clinic, and gynaecologists had low proportions of women returning for a smear test within the recommended time.

Home addresses were supplied for 916 (94\%) women in group A and 1332 (95\%) women in group B. Little difference was evident in adherence to the recommendation for repeat smear tests between the areas of residence. In group A 59 (10\%) of the women who lived in the metropolitan area of Melbourne and $29(10 \%)$ of those who lived in rural Victoria did not have a repeat smear test. In group B the figures were $151(16 \%)$ and $66(18 \%)$. In both groups higher proportions of the women who lived in the metropolitan area adhered to the recommended time $(47 \% v 43 \%$ in group $\mathrm{A}$ and $38 \% v 32 \%$ in group B). These proportions were not significantly different.

Table IV shows that apart from a high proportion of women in group A who did not return for a repeat smear test in the lowest group of social class no relation between social class and adherence to the recommendations was apparent.

\section{Discussion}

The results of this analysis are encouraging. There was good adherence to the recommendation for early repeat smear tests in two groups of women whose initial cytological abnormalities were not considered serious enough to warrant immediate referral to a gynaecologist. These findings contrast with those of other studies, in which, despite varying definitions of what constituted satisfactory follow up, there was a general despondency about success rates. ${ }^{6.9}$

The recent report of the Intercollegiate Working Party on Cervical Cytology Screening stated that a disturbingly high proportion of women who had abnormal smears had not been investigated adequately. ${ }^{6}$ Singer commented that many screening centres report satisfactory follow up and management for only $60 \%$ of cases. ${ }^{7}$ In a follow up study of 1347 women with mildly dyskaryotic smears for whom a repeat smear test was recommended Robertson et al reported 434 (32\%) cases in which the woman was lost to follow up before the importance of the abnormality could be assessed. ${ }^{8}$ Elwood et al determined that only 59\% of women with 
an abnormal smear in 1981 received satisfactory follow up. ${ }^{9}$

The rates of follow up in this study are minimum rates as we were unable to adjust for repeat smears that were examined in other laboratories in Victoria. Although a second smear test does not complete the appropriate management for women with the abnormalities described, the figures indicate a high degree of acceptance of initial management among women who lived in Victoria and their medical practitioners.

Older women adhered to the recommendations rather better than younger women. This is reassuring given the evidence that abnormalities in older women are less likely to regress and that they develop into more serious abnormalities generally more quickly than in younger women. ${ }^{10}$

The lack of a clear relation between social class and acceptance of repeat smear testing is also encouraging, indicating that if rates of participation in a screening programme can be increased among women from the lower social classes non-acceptance of the management of abnormalities should not inhibit the potential success of the programme.

The reminder letter potentially increased the proportion of women being screened substantially (by $18 \%$ in group A and $24 \%$ in group B). These results occurred in women whose adherence to the recommendations for repeat cervical smear tests was fairly high. The potential impact of reminder letters might be considerably greater where non-compliance was a more serious problem or if the letter was sent directly to the woman.

The reminder system described in this report should work in any country that provides screening for cervical cancer. Computerised record systems are desirable but not essential. To date, Australia has elected to take an opportunistic approach to preventing cervical cancer. The profile of the women being screened is biased towards younger women of high socioeconomic state. Women may elect to have their smear taken by any general practitioner, who is paid on a consultation basis. The reminder system of our service is neither labour intensive nor expensive. With the laboratory records stored on computer it is easy to program the computer to issue reminder letters at defined intervals. Such a system provides a fail safe mechanism for ensuring that reports of abnormal smears are not overlooked. The follow up section of the service is staffed by two clerical officers (out of a total staff of more than 60) and accounts for considerably less than $5 \%$ of the service's budget.

Achieving high rates of follow up smear tests and management in women with lesions that may be precursors for cervical cancer is critical to the success of a screening programme. Implementing fail safe systems for ensuring that such abnormalities are not overlooked deserves a high priority in the design of screening programmes. Funding bodies should not be allowed to believe that they have fulfilled their responsibility by providing laboratories with sufficient resources for only the initial tests. Failure to achieve appropriate management of abnormalities detected by screening tests will severely reduce the impact of the whole programme.

1 Mitchell H, Medley G, Drake M. Quality control measures for cervical cytology laboratories. Acta Cytol 1988;32:288-92.

2 Mitchell H, Medley G. Delay times to definitive diagnosis after an abnormal Pap smear. Aust N Z J Obstet Gynaecol 1987;27:283-6.

3 Pagano R, Chanen W, Rome RM, Johnstone NR. The significance of human papillomavirus atypia ("wart virus infection") found alone on cervical cytology screening. Aust $N Z$ f Obstet Gynaecol 1987;27:136-49.

4 Rome RM, Chanen W, Pagano R. The natural history of human papillomavirus (HPV) atypia of the cervix. Aust $N Z 7$ Obstet Gynaecol 1987:27: virus $287-90$.

5 Ross KN. Social area indicators of educational need. Australian Council for Educational Research Limited. Melbourne: Allanby Press, 1983.

6 Sharp F, Duncan ID, Evans DM, et al. Report of the intercollegiate working party on cervical cytology screening. London: Royal College of Obstetricians and on cervical cytology scree

Singer A. The abnormal cervical smear. Br Med f 1986;293:1551-6.

7 Singer A. The abnormal cervical smear. Br Med $\mathcal{F} 1986 ; 293: 1551-6$. Robertson JH, Woodend BE, Crozier EH, Hutchinson J. Risk of
cancer associated with mild dyskaryosis. Br Med f 1988;297:18-21.

cancer associated with mild dyskaryosis. Br Med $\mathcal{f}$ 1988;297:18-21.
9 Elwood JM, Cotton RE, Johnson J, Jones GM, Curnow J, Beaver MW. Are patients with abnormal cervical smears adequately managed? Br Med $\mathcal{J}$ 1984;289:891-4.

10 Prorok PC. Mathematical models and natural history in cervical cancer screening. In: Hakama M, Miller AB, Day NE, eds. Screening for cancer of the uterine cervix. Oxford: Oxford University Press, 1986:185-96.

\title{
Critical assessment of the use of growth monitoring for identifying high risk children in primary health care programmes
}

\author{
André Briend, Abdul Bari
}

Abstract

Objective-To see whether change in weight was a more useful index than weight for age in assessing the risk of dying among malnourished children.

Design-Prospective cohort study.

Setting-Rural community in Bangladesh being served by international health organisation.

Participants-1011 Children aged under 5, of whom 66 died.

End point-Efficient screening method for

The International Centre for Diarrhoeal Disease Research, Bangladesh André Briend, MD, nutritionist

Abdul Bari, MB, senior medical officer

Correspondence and requests for reprints to:

Dr A Briend, ICDDR, B, Box 128, Dhaka 1000 Bangladesh.

BrMed f 1989;298:1607-11 identifying malnourished children at risk of dying.

Measurements and main results-Weight was measured every month. Weight for age and monthly change in weight averaged over one and three months were calculated. Sensitivity and specificity curves were used to compare the values of these two variables in identifying children with a high risk of dying. Weight for age was more sensitive than change in weight at all levels of specificity. Changes in weight, however, were independently related to the risk of dying even when intercurrent diseases and low weight for age were taken into account.
Conclusions-For identifying children with a high risk of dying weight for age is a more efficient screening tool than a recent change in weight. Growth monitoring as currently recommended for primary health care programmes in developing countries does not seem to be the most effective approach in identifying children in need of urgent help.

\section{Introduction}

Growth monitoring is a key component of primary health care programmes aimed at bringing about a "child survival revolution" in the coming years.' The rationale for growth monitoring is that most mothers of malnourished children do not know that anything is wrong and that recognising abnormal growth will prompt them to take action to prevent their child's death. ${ }^{2}$ Though never stated explicitly, the concept underlying this approach is that children with low weight gain as detected by regular weighing are thought to be more at risk than those who are severely 